\title{
Effects of insulating layer on the performance of thin film electroluminescent devices
}

\author{
M K JAYARAJ* and C P G VALLABHAN \\ Department of Physics, Cochin University of Science and Technology, Cochin 682022 , \\ India \\ *Present address: Physical Research Laboratory, Navrangpura, Ahmedabad 380 009, India \\ MS received 27 August 1990; revised 21 January 1991
}

\begin{abstract}
Thin film electroluminescent devices were fabricated with active layer of $\mathrm{ZnS}: \mathrm{Mn}$ and different insulators viz $\mathrm{Sm}_{2} \mathrm{O}_{3}, \mathrm{Eu}_{2} \mathrm{O}_{3}, \mathrm{Na}_{3} \mathrm{AlF}_{6}, \mathrm{MgF}_{2}, \mathrm{CeO}_{2}$ and $\mathrm{SiO}$ in MIS and MISIM structure. The threshold voltage for light emission in AC thin film electroluminescent devices of MIS and MISIM structures is found to depend on the dielectric properties of insulating materials. The observed threshold voltage for these devices and its variations for devices with different insulators are explained using the equivalent circuit for the device and the dielectric properties of the insulting material used for the preparation of device. Variation of threshold voltage with operating time is also studied for some of the devices.
\end{abstract}

Keywords. Electroluminescent devices; threshold voltage; insulating layer.

\section{Introduction}

AC thin film electroluminescent (ACTFEL) devices have been actively investigated in recent years (Inoguchi and Mito 1977; Lehmann 1980; Kutty 1985) since they exhibit a number of attractive properties such as low power dissipation and fast response along with the possibility of providing large area, completely solid-state multicolour flat panel displays. The most popular double insulating devices have high brightness $\left(>1000 \mathrm{~cd} / \mathrm{m}^{2}\right)$ and long life $(\sim 2000 \mathrm{~h})$ but require operating voltages of about 150 volts (Inoguchi and Mito 1977).

Devices based on metal-insulator-semiconductor structure (MIS) have been suggested as one way of reducing the driving voltage of the TFEL devices (Kozawaguchi et al 1982). According to Howard (1977), to obtain high brightness and better efficiency for these devices, the insulator film must satisfy the condition that the product of its dielectric constant $(\varepsilon)$ and breakdown voltage must at least be three times higher than that of the active layer. This implies that low voltage operation can be obtained without sacrificing the brightness or efficiency by using insulators of high dielectric constant and preferably with high breakdown strength. The performance of ACTFEL devices depends on the thickness of $\mathrm{ZnS}: \mathrm{Mn}$ layer (Tornqvist et al 1983). The threshold voltage can be reduced either by reducing the thickness of insulating layer or active layer or both. In order to fabricate legible low voltage and high brightness TFEL devices in MIS structure with $\mathrm{ZnS}: \mathrm{Mn}$, insulating layers of different figure of merit $\left(\mathrm{Sm}_{2} \mathrm{O}_{3}, \mathrm{Eu}_{2} \mathrm{O}_{3}, \mathrm{Na}_{3} \mathrm{AlF}_{6}, \mathrm{MgF}_{2}, \mathrm{CeO}_{2}\right.$, and $\mathrm{SiO}$ ) have been investigated here. For low voltage and high brightness the optimal thickness of $\mathrm{ZnS}$ layer and insulator (in the case of $\mathrm{Eu}_{2} \mathrm{O}_{3}$ and $\mathrm{Sm}_{2} \mathrm{O}_{3}$

\footnotetext{
*For correspondence.
} 
films) is found to be for a thickness ratio lying between 1 and 2 (Jayaraj and Vallabhan 1990a). This suggests the possibility of lowering the voltage using insulators of high figure of merit in MIS-structured devices.

\section{Experimental}

The schematic structure of the TFEL device is shown in figure 1. A ZnS:Mn phosphor layer is evaporated on to a $\mathrm{SnO}_{2}$-coated glass substrate by electron beam evaporation. The $\mathrm{ZnS}: \mathrm{Mn}$ phosphors were prepared in the laboratory by a slurrying technique (Jayaraj and Vallabhan 1989a). The transparent electrodes were prepared by spray pyrolysis. Any one of the insulating layers of $\mathrm{Sm}_{2} \mathrm{O}_{3}, \mathrm{Eu}_{2} \mathrm{O}_{3}$, $\mathrm{MgF}_{2}, \mathrm{Na}_{3} \mathrm{AlF}_{6}, \mathrm{SiO}$, and $\mathrm{CeO}_{2}$ was deposited by electron beam evaporation. During deposition the substrate temperature was kept at $423 \mathrm{~K}$. The experimental investigations were carried out using a TFEL cells of emitting area $0.5 \times 1 \mathrm{~cm}^{2}$. A variable frequency sine/square wave generator was used to excite the cell along with a series resistor $100 \mathrm{~K}$ ohm which limits the current through the device. The EL emission spectra were recorded with the help of a $0.5 \mathrm{~m}$ Jarrel-Ash scanning spectrometer coupled with an EMI9683 KQB photomultiplier tube (PMT) having S-20 cathode. The PMT current was amplified with low noise high gain PMT preamplifier (Pillai and Vallabhan 1982) and recorded by a strip chart recorder. The EL emission intensity was measured using a PMT with S-1 cathode. For capacitance and loss factor measurements, thin films of about $2000 \AA$ were made in sandwich structure between two aluminum electrodes having an area $1 \mathrm{~cm}^{2}$. The capacitance and loss factors were measured using a LCZ meter (Hewlett-Packard 4277A) under a vacuum of $10^{-2}$ torr.

\section{Results and discussion}

The EL spectra of all the devices are the same as those of conventional ITO- $\mathrm{Y}_{2} \mathrm{O}_{3}$ $\mathrm{ZnS}: \mathrm{Mn}-\mathrm{Y}_{2} \mathrm{O}_{3}-\mathrm{Al}$ device (Inoguchi and Mito 1977). The brightness voltage (BV) characteristics of the device with $\mathrm{MgF}_{2}$ and $\mathrm{Eu}_{2} \mathrm{O}_{3}$ insulating layers shows that the threshold voltage for the onset of emission increases with increase of excitation frequency (in the present experiments frequency was varied from $50 \mathrm{~Hz}$ to $5 \mathrm{kHz}$ ). This anomalous behaviour is explained elsewhere (Pillai and Vallabhan 1986; Jayaraj and Vallabhan 1990a). Figure 2 shows the B/V characteristics of the MIS devices with an active layer thickness $0.3 \mu \mathrm{m}$ and insulator thickness $0.2 \mu \mathrm{m}$ fabricated under similar conditions. It is observed that the threshold voltage for the onset of emission decreased with decrease of $\mathrm{ZnS}$ : Mn active layer thickness. This

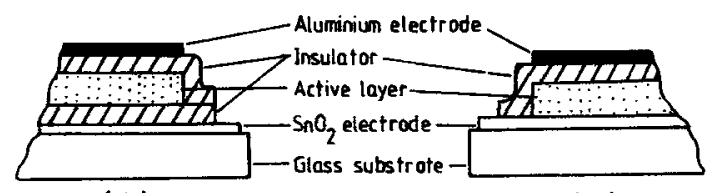

(A)

(B)

Figure 1. Structure of a typical TFEL (A) MISIM, (B) MIS device. 


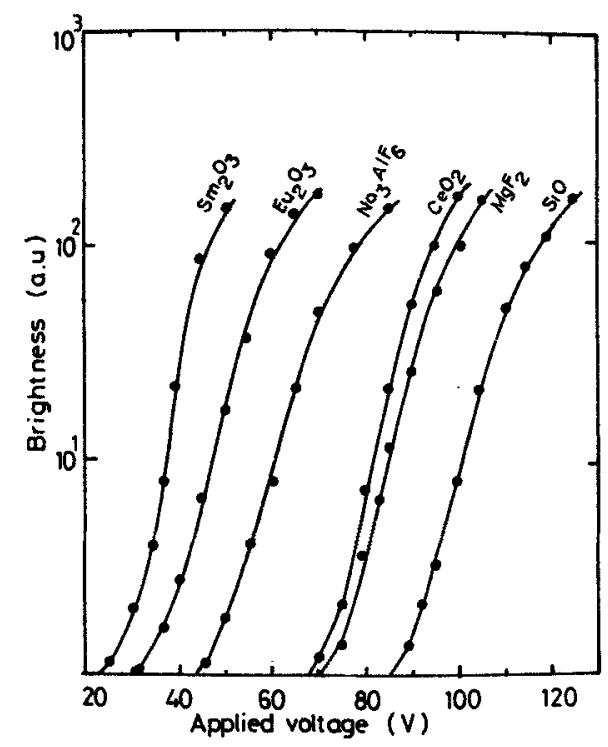

Figure 2. BV characteristics of MIS TFEL devices with different insulating layers under $1 \mathrm{kHz}$ sine wave excitation.

was again reduced with the reduction of insulator thickness (whereas the brightness is found to increase with increase of $\mathrm{ZnS}: \mathrm{Mn}$ layer thickness). Thus the driving voltage of TFEL devices can be reduced either by reducing the thickness of active layer or insulator or both. But when the insulator layer is too thin there is a possibility of breakdown while thick layers of insulator requires higher operating voltage. The optimal condition for MIS structure devices for low voltage operation is when the thickness ratio between active layer and insulator layer lies between 1 and 2. A detailed discussion on this aspect is given elsewhere (Jayaraj and Vallabhan 1990a). The brightness of a typical EL cell is estimated in absolute units using a PMT having a spectral response closely matching the sensitivity of human eye and it is found to be $1450 \mathrm{ft}$-lamberts.

The BV characteristics of metal-insulator-semiconductor-insulator-metal (MISIM) devices with $\mathrm{ZnS}: \mathrm{Mn} 0.6 \mu \mathrm{m}$ and insulator layer of $0.3 \mu \mathrm{m}$ is shown in figure 3 . From the slope of BV characteristics (figures 2 and 3 ) it can be seen that the doubly insulated TFEL devices show a steep increase in brightness when the applied voltage exceeds a certain threshold; whereas in MIS TFEL devices the brightness increases steeply. In both types of devices the brightness level saturates at high applied voltages. The MIS TFEL device has no insulator between one of the electrodes and the $\mathrm{ZnS}$ layer. Hence carriers could readily be injected from the electrode or released from the layer with the result that no carriers will accumulate near $\mathrm{ZnS}$ electrode interface, whereas in MISIM devices the charge will be stored at $\mathrm{ZnS}$-insulator interface. As a consequence electric field induced by space charge at the $\mathrm{ZnS}$-insulator layer add to the electric field produced by the applied voltage (Ogawa et al 1984). The trapped holes inside the $\mathrm{ZnS}$ layer can generate an internal field which increases the probability of electrons tunnelling through the $\mathrm{ZnS}$ insulator barrier. Moreover, TFEL device being a capacitive load, conduction current which contributes to luminescence is different at high voltages due to 


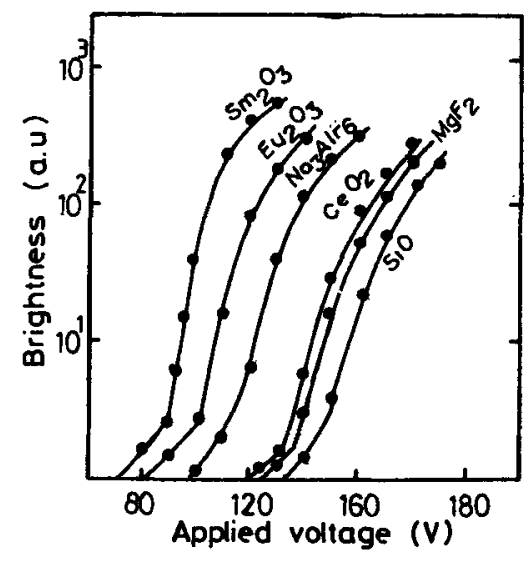

Figure 3. BV characteristics of MISIM TFEL devices with different insulating layers under $1 \mathrm{kHz}$ sine wave excitation.

Table 1. Threshold voltage $V_{\text {th }}$ for MISIM and MIS TFEL devices and dielectric constants and breakdown strength of insulator used for device fabrication.

\begin{tabular}{lccccc}
\hline Material & Thickness $(\mu \mathrm{m})$ & $\varepsilon$ & $\begin{array}{c}\text { Breakdown } \\
\text { strength V/cm } \\
\left(\times 10^{6}\right)\end{array}$ & $\begin{array}{c}V_{\text {th }} \text { for MISIM } \\
\text { TFEL device } \\
\text { (volts) }\end{array}$ & $\begin{array}{c}V_{\text {th }} \text { MIS } \\
\text { TFEL } \\
\text { device }\end{array}$ \\
\hline $\mathrm{Sm}_{2} \mathrm{O}_{3}$ & 0.2 & 43 & 2 & 80 & 25 \\
$\mathrm{Eu}_{2} \mathrm{O}_{3}$ & 0.2 & $15-21$ & 2 & 90 & 30 \\
$\mathrm{Na}_{3} \mathrm{AlF}_{6}$ & 0.2 & $6 \cdot 6$ & $2 \cdot 6$ & 100 & 45 \\
$\mathrm{CeO}_{2}$ & 0.2 & 4.8 & 3 & 120 & 65 \\
$\mathrm{MgF}_{2}$ & 0.2 & 4.9 & 2 & 125 & 70 \\
$\mathrm{SiO}$ & 0.2 & $3 \cdot 2-5 \cdot 2$ & 2 & 130 & 80 \\
\hline
\end{tabular}

nonlinear effects. These factors may account for the sudden increase in slope of the BV curves observed for MISIM structures.

From the BV curves it is also clear that the threshold voltage for the onset of emission is different for devices with different insulators. The threshold voltage $\left(V_{\text {th }}\right)$ for the onset of emission depends on the dielectric properties of the materials used and is minimum for devices with $\mathrm{Sm}_{2} \mathrm{O}_{3}$ and $\mathrm{Eu}_{2} \mathrm{O}_{3}$ as insulators while it is high for devices with $\mathrm{SiO}$ as insulator. Table 1 gives the materials used here as insulating layer in TFEL devices, their dielectric constants and the respective threshold voltage for MISIM and MIS structured devices. This variation of threshold voltage for different insulating layers, can be explained by making use of the equivalent circuit of the device as shown in figure 4 . The TFEL can be considered as two series capacitance $C_{i}$ and $C_{s}$ due to insulator and the active layer respectively. Here $R_{i}$ is an additional resistance included to account for the leakage currents. It can be visualized that if $V$ is the applied voltage and $U$ the voltage appearing across the active layer, then

$$
U=Z_{s} /\left(Z_{s}+Z_{i}\right) V
$$

where $Z_{i}$ and $Z_{s}$ are the impedance of the insulating and active layers. At a 


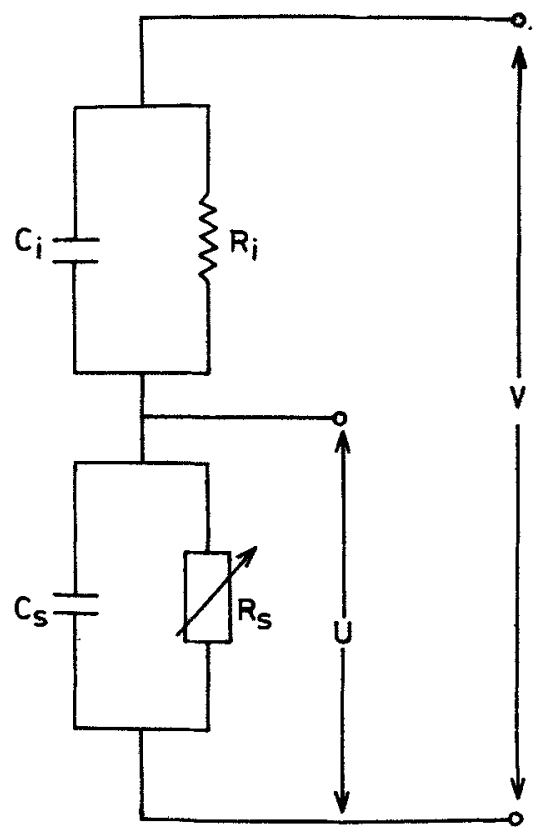

Figure 4. Equivalent circuit.

particular frequency $\omega$

$$
\begin{aligned}
& U_{\mathrm{th}}=\frac{Z_{s}(\omega)}{Z_{i}(\omega)+Z_{s}(\omega)} V_{\mathrm{th}}, \\
& U_{\mathrm{th}}=\frac{R_{s}\left(1+C_{i} \omega R_{i}\right)}{R_{s}+R_{i}+\omega R_{i} R_{s}\left(C_{i}+C_{s}\right)} V_{\mathrm{th}} .
\end{aligned}
$$

Assuming the leakage resistance to be very high

$$
U_{\mathrm{th}}=C_{i} /\left(C_{i}+C_{s}\right) V_{\mathrm{th}} \text {. }
$$

Here $C_{s}$ is constant since the active layer (in the present case $\mathrm{ZnS}$ : Mn films having dielectric constant $\varepsilon$ about 7) of same thickness is used in all the devices while $C_{i}$ is different because the insulator layers used are materials with different dielectric constant even though the thickness is the same in all the cases. However $U_{\text {th }}$ i.e. the threshold voltage for the onset of emission (or voltage across the active layer) is a constant. Devices with insulators of high dielectric constant will have high $C_{i}$ value which in turn increases the applied voltage for the onset of emission $\left(V_{t h}\right)$ as determined by (4) since $U_{\text {th }}$ has to remain constant. This evidently explains the low threshold voltage for the onset of emission for devices with $\mathrm{Sm}_{2} \mathrm{O}_{3}$ insulating film which has a higher value of $\varepsilon(\approx 42)$.

\subsection{Ageing effects}

It is a well known fact that threshold voltage for TFEL devices increases with operating time and then gradually becomes constant (Inoguchi et al 1977). Ageing of more than $100 \mathrm{~h}$ has been required to stabilize the device characteristics. In the 
present case, devices with $\mathrm{Sm}_{2} \mathrm{O}_{3}$ and $\mathrm{Eu}_{2} \mathrm{O}_{3}$ as insulating layers were subjected to ageing studies. It is observed that, in the case of devices fabricated with insulators $\left(\mathrm{Sm}_{2} \mathrm{O}_{3}\right.$ and $\left.\mathrm{Eu}_{2} \mathrm{O}_{3}\right)$ and active layer $(\mathrm{ZnS})$ deposited at higher substrate temperature $\left(T_{s}=423 \mathrm{~K}\right)$ do not show any appreciable variation in threshold voltage with ageing or operating time (figures 5 and 6). But devices prepared with same insulators deposited at a lower substrate temperature $\left(T_{s}=300 \mathrm{~K}\right)$ and active layer at $423 \mathrm{~K}$ show marked variation in the threshold voltage. This phenomenon can also be accounted for in terms of the dielectric properties of the insulating materials. The dielectric constant of $\mathrm{Eu}_{2} \mathrm{O}_{3}$ and $\mathrm{Sm}_{2} \mathrm{O}_{3}$ prepared at $T_{s}=300 \mathrm{~K}$ decrease with ageing time. The rare earth oxide films require prolonged annealing of about $200 \mathrm{~h}$ to have a stable dielectric constant (Nakane et al 1979). It is found that $\mathrm{Eu}_{2} \mathrm{O}_{3}$ and $\mathrm{Sm}_{2} \mathrm{O}_{3}$ prepared at substrate temperature $423 \mathrm{~K}$ will have a dielectric constant and loss factor which are independent of ageing time. These films deposited at higher substrate temperature exhibit better dielectric properties owing to improved stoichiometry of the films (Jayaraj and Vallabhan 1989b, 1990b). The variation of $\varepsilon$ with time for $\mathrm{Sm}_{2} \mathrm{O}_{3}$ and $\mathrm{Eu}_{2} \mathrm{O}_{3}$ films prepared at $423 \mathrm{~K}$ and $300 \mathrm{~K}$ are shown in figures 5 and 6 . The threshold voltage varies with operating time for devices prepared with insulators at $T_{s}=300 \mathrm{~K}$ because $\varepsilon$ decreases with ageing time which in turn changes $C_{i}$ and hence $V_{\text {th }}$, while device prepared at $T_{s}=423 \mathrm{~K}$ do not

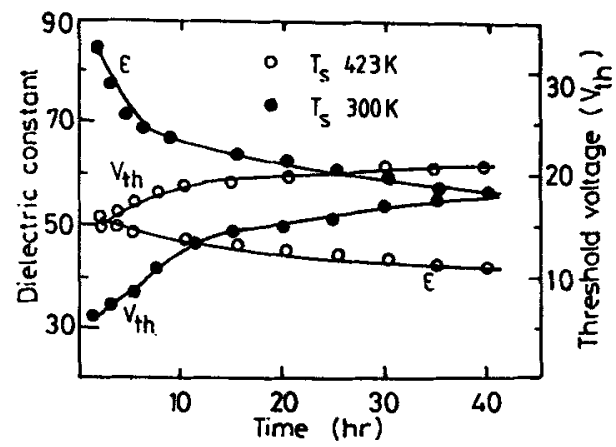

Figure 5. Variation of $V_{\text {th }}$ and $\varepsilon$ (at $1 \mathrm{kHz}$ ) with ageing time for $\mathrm{Sm}_{2} \mathrm{O}_{3}$-based MIS TFEL device.

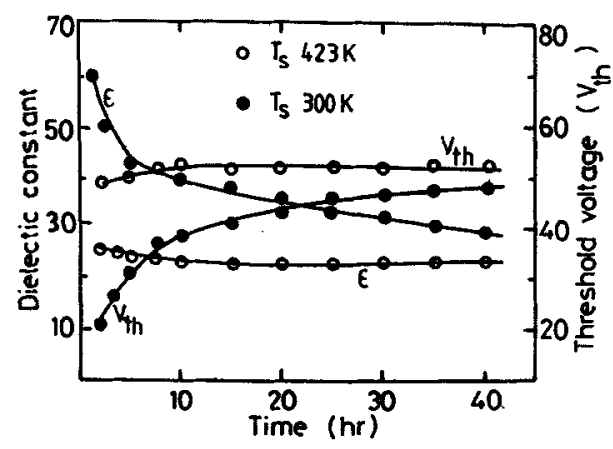

Figure 6. Variation of $V_{\text {th }}$ and $\varepsilon\left(\right.$ at $1 \mathrm{kHz}$ ) with ageing time for $\mathrm{Eu}_{2} \mathrm{O}_{3}$-based MIS TFEL devices. 
show any variation in threshold voltage. $C_{s}$, the capacitance due to $\mathrm{ZnS}$ layer, is almost a constant and hence it does not affect the operating characteristics of the device. Hence the variation of $V_{\text {th }}$ is due to variation in insulating film properties.

\section{Conclusions}

TFEL devices with MIS structure as well as double insulating MIS structure have been fabricated using $\mathrm{ZnS}: \mathrm{Mn}$ as an active layer and different insulators. $\mathrm{Sm}_{2} \mathrm{O}_{3}$ is a better insulator for low voltage operation without loss in brightness and EL emission characteristics. The threshold voltage for the onset of emission is low for $\mathrm{Sm}_{2} \mathrm{O}_{3}$-based devices, while it is high for SiO-based devices. This behaviour is attributed to the high dielectric constant of the insulating material used in the fabrication of devices. Devices in which $\mathrm{Sm}_{2} \mathrm{O}_{3}$ or $\mathrm{Eu}_{2} \mathrm{O}_{3}$ deposited at higher $(423 \mathrm{~K})$ substrate temperature do not show significant variation in threshold voltage with ageing time.

\section{Acknowledgement}

One of the authors (MKJ) is thankful to the University Grants Commission for the award of a fellowship.

\section{References}

Howard W E 1977 Proc. SID 18119

Inoguchi T and Mito S 1977 Topics in applied physics: Vol. 17, Electroluminescence (ed.) J I Pankove, (Berlin: Springer Verlag) p 197

Jayaraj M K and Vallabhan C P G 1990a J. Phys. D23 1706

Jayaraj M K and Vallabhan C P G 1989a J. Phys. D22 1380

Jayaraj M K and Vallabhan C P G 1989b Thin Solid Films 17759

Jayaraj M K and Vallabhan C P G 1990b Thin Solid Films 196 (in press)

Kozawaguchi H, Ohwaki J, Tsujiyama B and Murase K 1982 SID Int. Symp. Dig. Tech pap XII San Diego CA (Los Angeles CA: Society for Information Display) p. 126

Kutty T R N 1985 Thin Solid Films 127223

Lehman W 1980 Displays 229

Nakane H, Noya S, Kurki S and Matsumoto G 1979 Thin Solid Films 59291

Ogawa M, Nakada S, Sakurai M and Yoshida T 1984 J. Lumin. 2911

Ohwaki J, Kozawaguchi H and Tsujiyama B 1983 Jpn. J. Appl. Phys. 221133

Pillai S M and Vallabhan C P G 1982 J. Instrum. Soc. India 127

Pillai S M and Vallabhan C P G 1986 Electron. Lett. 22668

Tornquist R, Anston J, Skarp J and Tanninen V P 1983 IEEE Trans. Electron. Dev ED30 468 